\section{Beginning Literacy: The Small-Unit Versus Large-Unit Debate Continues}

\author{
JULIET TWIST
}

\section{Abstract:}

This article presents a review of the literature on the small-versus large-unit debate, followed by an analysis of the Ready to Read Teacher Support Material in order to determine where it stands in relation to the issue over whether only grapheme-phoneme correspondences should be taught to beginning readers, or whether they should also be taught rime-analogy strategies. The literature review shows the small-units-first argument as the more robust, and the analysis of the Ready to Read support material shows the small-units-first aroument has been relatively more influential in the development of teaching suggestions for readers at the beginning of instruction.

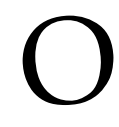

ne widespread view of how children read unfamiliar words is that they first use small units, that is, grapheme-phoneme correspondences, and only later in reading development do they make use of larger units such as onsets and rimes. A contrasting view emphasizes children's early ability to use onsets and rimes to make larger-unit spelling-to-sound correspondences. This article is concerned with investigating these two theories in an attempt to discover if application of one or the other will result in more effective reading instruction. It also analyses the Ready to Read Teacher Support Material (Ministry of Education, 2001, 2002, 2003) in order to determine where that resource stands in relation to the small- versus large-unit debate. The first section provides a review of the literature, and the second provides an analysis of the Ready to Read support material as published up to May, 2004. The support material comprises suggestions for teachers on how to use the Ready to Read books and poem cards, published primarily as instructional texts to be used by children in the first three years of school. As of May 2004, the notes for the poem cards and Emergent and Early level texts have been published; the Fluency level notes will be published later this year, and new text notes at various levels added to the folder of notes as texts are published.

Some definitions: The onset of a spoken one-syllable word corresponds with the initial consonant/s in the written form. The onset of hat is " $h$ ", the onset of blue is "bl", and the onset of street is "str". The rime of a spoken one-syllable word corresponds with the vowel/s and any final consonants in the written form. The rime of hat is "at", the rime of blue is "ue", and the rime of street is "eet". Note that the number of rimes will always correspond with the number of syllables, but the syllable onset is not a necessary component of a syllable. For example, a word with two syllables such as planet (plan / et) has two rimes - "an" and "et", and only one onset - "pl". A phoneme is the smallest unit of sound that changes meaning in language. Hat and ham differ by a final phoneme, and hat and hot differ by a medial phoneme. Although the onset of hat and the rime of blue are single phonemes, the onset of blue and the rimes of hat and street correspond with two phonemes, and the onset of street corresponds with three. A grapheme is the graphic representation of a phoneme. In an alphabetic system like English, graphemes take the form of letters. In blue the phoneme " $\mathrm{b}$ " is represented by the letter (grapheme) $b$, the phoneme " 1 " by the letter (grapheme) $l$, and the phoneme "ue" by the letters (graphemes) ue.

\section{Literature Review}

Research supporting the teaching of onset-rime strategies as soon as children begin school rests on the argument that pre-readers' phonological knowledge is largely about onsets and rimes, and not about phonemes. Goswami and Bryant (1990) argue that, from the very beginning of literacy instruction, children learn to associate onsets and rimes with strings of letters; they may even require very little explicit instruction to do so. This argument proposes that teachers take advantage of the phonological skills children come to school with, and teach onset-rime at the outset of reading instruction.

Related research also points to the relative difficulty of using grapheme-phoneme correspondences when decoding. Tunmer (1994), Tunmer and Chapman (1999), and Goswami and East (2000) suggest 
that onset-rime units are more accessible to young children because their use involves less processing. That is, it is easier to blend the onset and rime of the word street (i.e., "str" "eet") than it is to blend the individual phonemes (i.e., " $\mathrm{s}$ " " $\mathrm{t}$ " " $\mathrm{r}$ " "ee" " $\mathrm{t}$ "). Wise (1992) reports that blending onset and rime units into words is much easier than blending phoneme units for beginning readers. Treiman (1985) also reports that young children are more successful at breaking apart the onset and rime in a spoken word than breaking the word into its individual phonemes, and Treiman and Zukowski (1991) report that four- and five-year-olds' large unit awareness is superior to their awareness of phonemes, and that comparable awareness at the phoneme level was only found amongst six-year-olds. They argue that the awareness of small units is the result of literacy instruction, and is not a skill children possess prior to starting school. This is supported by Morais, Cary, Alegria, and Bertelson's (1979) finding that illiterate adults, and even illiterate poets (Morais, 1991), generally lack phonemic awareness.

Findings to the contrary report that phonological awareness normally develops from small-to-large units, that is, from an awareness of phonemes to a later awareness of onset-rime (Duncan, Seymour, \& Hill, 1997, 2000; Seymour, Duncan, \& Bolik, 1999), with Semour et al. suggesting that it is not until the age of approximately seven years that most children are able to use rime-related strategies. Goswami (1999a) and Goswami and East (2000), however, argue that the findings of Duncan et al. (1997) were not surprising, considering the children tested were receiving phoneme-level, and not rime-level decoding instruction at school.

In support of the small-units-first theory of phonological development, Muter, Hulme, Snowling, and Taylor (1997) found that the ability to segment words into their individual phonemes was strongly correlated with reading attainment at the end of the first year at school, but that onset-rime was not. Bryant (1998) raised concerns over methodological weaknesses of the above research, but when these were addressed (Hulme et. al, 2002) phoneme awareness was again found to be the best predictor of reading skill. Onset-rime made no additional contribution.

A systematic account of what might be involved in the small-to-large unit theory of reading development is provided by Ehri (1992, 1995, 1998). According to Ehri, children's reading development moves through four phases. In phase one, readers select single salient visual clues to remember words. Such clues could be the two humps in the middle of camel, the hexagonal shape of a STOP sign, or a thumbprint on a page (Gough, Juel, \& Griffiths, 1992). Most importantly, no grapheme-phoneme correspondences are involved. In phase two, readers form partial connections between only some of the letters in words and sounds detected in the words' pronunciations often the first and final letters. In phase three, readers form more complete connections between letters and sounds. Finally, in phase four, readers recognize letter patterns, and so nolonger have to decode phoneme by phoneme as in phase three. Crucially, it is only at this point that they can use large units like onsets and rimes to read unfamiliar words

\section{Rime analogy: Is it relevant?}

However, another account of reading development argues that very young children are able to identify the onset and rime in one-syllable words, and then use the rime unit to read unfamiliar words by analogy. They do this by finding an analogue word that has a matching rime from within their existing reading vocabulary. This account is based on research into pre-readers' and beginning readers' awareness of rhyme. It is this awareness that is claimed to be a significant predictor of reading development, not awareness of phonemes (Bradley \& Bryant, 1978, 1983; Bryant, MacLean, Bradley, \& Crossland, 1990; MacLean, Bryant, \& Bradley, 1987). Bryant et al. (1990) reported a significant relationship between nursery rhyme knowledge at three years of age, and success in reading and spelling at ages five and six, even when factors such as social background and IQ were controlled. It has also been found that children reading below their chronological age have less well-developed rhyming skills than younger children reading at the same level (Bradley \& Bryant, 1983).

Goswami (1986, 1988, 1990a, 1990b, 1993) and Goswami and Bryant (1990) argue that the special link between rhyming skills and reading development can be described as follows: children who have put words into rhyming categories before they begin to learn to read, may, once they begin to learn to read, be able to see that words that rhyme also often share the same spelling patterns. That is, they may be able to use these similarities in spelling to make inferences (analogies) about how unfamiliar written words will sound. This ability to make 
inferences about similarities in sound from similarities in spelling is known as orthographic analogy. It is also argued that in learning to analogize using rimes, children will necessarily learn some grapheme-phoneme relationships (i.e., especially related to the onset and the final consonant of the rime) and will also necessarily learn how to blend (i.e., the onset and the rime). Since these two skills are essential ingredients in learning how to read using grapheme-phoneme units, teaching beginners to read by rime-analogy is thought to act as a bridge to phonological recoding at the phoneme level (Goswami, 1990a, 1990b, 1999a; Tunmer, 1994).

This, and later research (Goswami, 1990a, 1990b, 1993; Goswami \& Bryant, 1990), demonstrated that young children can use a rime-analogy strategy to read new words. However, it must be noted that there is little evidence to support children's use of a rime-analogy strategy from the very outset of reading instruction, since the mean reading age of subjects in most of Goswami's research was between six and a half and seven years. The only notable exception is in Goswami and East (2000), where the mean reading age in Experiment Two was five years, eight months. Goswami's work has received further criticism. In research by Muter, Snowling, and Taylor (1994), subjects were first taught the pronunciation of clue words, then later asked to read a series of words analogous with each clue. Half the subjects had the clue words exposed, while half did not. Muter and colleagues found that when the clue was hidden, the children's ability to use analogy was substantially reduced, leading them to doubt that beginning readers can spontaneously use this strategy. In response, Goswami (1999a) points out that the clue word task was not developed as a naturalistic measure of independent classroom reading behaviour, but was developed to test for the analogy mechanism in young children - to test if young children could make analogies, or if they could not.

It has also been argued that beginning readers are unlikely to be able to use a rime-analogy strategy because their reading vocabularies are insufficiently large. In order to read a new word by analogy, the reader must have more than one word with the same rime stored in memory (Savage \& Stuart, 1998); it is this stored word that is used by the reader as the basis for making an inference about shared spelling and pronunciation. Accordingly, it has been argued that beginning readers are very unlikely to have enough words stored in memory to be able to read using a rime-analogy strategy with any degree of frequency. Bowey and Hansen (1994), Bowey and Underwood (1996), and Bowey, Vaughan, and Hansen (1998), all found that the number of analogies children make increases as their reading vocabularies increase, with Bowey and Hansen (1994) reporting that only more advanced first-grade readers showed an ability to use an orthographic rime strategy. These researchers have interpreted their findings as evidence that rime analogies are not available to beginning readers; they are in fact, a late-emerging development.

Goswami (1986, 1988, 1999a), Goswami and Bryant (1990), and Goswami and East (2000) however, have no argument with the finding that younger readers make fewer rime analogies because they have smaller reading vocabularies. Indeed, they share this finding, agreeing that children cannot base analogies on a reading vocabulary they do not possess. What is at issue, argue Goswami and colleagues, is whether or not beginning readers are sensitive to the frequency with which a given rime occurs in their reading vocabularies. Goswami (1999a) also states that in order to facilitate this sensitivity, teachers should respond to the work of Leslie and Calhoon (1995) and Treiman, Goswami and Bruck (1990), and introduce words from large rime neighbourhoods first. That is, teachers should introduce words that share a rime with many other words (e.g., dip, hip, chip) before they introduce words from a small rime neighbourhood (e.g., seem, deem, teem), because words containing rimes which occur relatively frequently in children's reading experience will be more frequently reinforced while they are reading natural text. However, although Calhoon and Leslie (2002) and Leslie and Calhoon (1995) advocate teaching rime-analogy strategies to children who have reached the partial alphabetic phase (see Ehri, 1992, 1995, 1998), they argue that first graders will have an insufficient number of words fully represented in memory to be sensitive to the frequency with which rimes occur in their reading vocabularies.

Analogy use by beginning readers at the level of onset-rime is also questioned by Ehri and Robbins (1992) because, they argue, in order to have awareness at the level of onset-rime, readers must first have an awareness of grapheme-phoneme correspondences. This work is based on Ehri's phases of reading development $(1992,1995,1998)$ discussed above, but while not supporting Ehri's account of reading development, Goswami acknowledges that beginning readers need to 
learn grapheme-phoneme correspondences (Goswami \& Bryant, 1990). Children, argues Goswami (1990a), need to be able to delete phonemes in order to make an analogy between words (e.g., between beak and peak) because the reader needs to see both words as -eak before an analogy can be made. They also need to be able to decode onsets to use analogies, and to learn about the vowels and final consonants in the rime (Goswami 1999a).

\section{Rimes and phonological priming}

However, in making this acknowledgement, Goswami exposes a weakness in her argument. It is when this acknowledgement is placed alongside the argument that non-readers (children yet to score on a standardized reading test) occasionally show an ability to decode at the level of onset-rime (Goswami, 1986, 1988; Goswami \& Bryant, 1990), that a contradiction becomes apparent. Goswami appears to be arguing both that grapheme-phoneme correspondences are necessary to decoding using a rime-analogy strategy, and that non-readers (who, even Goswami concedes are not yet reading), can nonetheless decode at this level. Ehri and Robbins (1992), whose work Goswami (1999a) cites as evidence of pre-readers using rime analogies, suggest that preand even beginning readers cannot use onset-rime analogy strategies, and that their and Goswami's results may be due to the effects of phonological priming.

Phonological priming refers to the researcher's decoding of the clue word in Goswami's clue word task prompting a correct reading of the target word without the child taking any notice of shared spelling. In other words, it is the sound structure (the phonology) of the clue word, rather than its physical (orthographic) similarities with the target word that the child exploits during the clue word task. Goswami (1999a) acknowledges that a small phonological priming effect may occur. But, she argues, if all rime analogy effects were due to phonological priming, children would be as likely to make analogies when the clue and target words do not share a spelling pattern (i.e., head priming a correct reading of said) as when they do (e.g., head-bread). Goswami's (1990b) research reports that this is not so, with larger analogy effects found for words that share spelling patterns.

Bowey et al. (1998) argue that Goswami does not do enough to dismiss a phonological priming account of children's use of rime analogy. They demonstrate that if test scores are adjusted to take phonological priming into account, there is no difference in children's performance at making rime analogies, as compared with analogies based on the onset-vowel as a unit. Goswami (1999a, 1999b) points to procedural weaknesses in this research, suggesting the methodology encouraged phonological priming effects. However, when Wood (2002) revised the procedure used by Bowey et al. in order to address Goswami's concerns, the original results were verified. A further addition to the debate is provided by Savage and Stuart's (1998) use of a modified clue word task. This work successfully demonstrated that young children can use rime analogies even when the clue word is only heard and not seen, prompting the authors to speculate that this effect may be due to the phonological (spoken) prompt stimulating orthographic knowledge in memory of known words with the same rime.

Evidence also suggests that it may be Goswami's clue word task itself that encourages a phonological priming effect (Wood, 2002). Ironically, it is Goswami (1990b) who has demonstrated an alternative test that appears to eliminate the effect. She found that when children were given a more naturalistic piece of prose instead of words in isolation as in the clue word task, no phonological priming effect was evident, while the rime-analogy effect remained. It has been suggested (Goswami, 1990b; Wood, 2002) that this may be because the phonological salience of common rhyme patterns is reduced when a prose passage is used.

\section{Spelling consistency for rime units}

The use of rime units is also proposed as a means of coping with the irregular English orthography, although it is dismissed as a useful form of beginning instruction by those arguing that beginning readers first need to acquire a sufficiently large reading vocabulary and phoneme-level awareness (Macmillan, 2002). Those advocating the teaching of rime units at the outset of reading instruction draw attention to the lack of inherent principles within the English spelling system, describing it as arbitrary, ambiguous, and not easily accessed by young children (Johnson, 1999; Moustafa, 1997). For example, Moustafa (p. 86) points out that the spelling of blue might just as easily have been bloe (as in shoe), blo (as in to), blew (as in threw), or blough (as in through). Indeed, it has been demonstrated that of over thirty 
vowel-related spelling generalizations analysed, only half worked over fifty percent of the time (Clymer, 1963, cited by Moustafa, 1997, p. 8).

Because spelling-sound correspondences at the graphemephoneme level are not consistently predictable in English, it is argued that decoding on a letter-by-letter basis is not sufficient, and that beginning readers could usefully learn to decode using rime units (Treiman, 1992; Treiman, Mullenix, Bijeljac-Babic, \& Richmond-Welty, 1995). Through the use of these units, an irregularly spelled word (that is, a word that cannot be spelled on a letter-by-letter basis), becomes regular, because the reader learns that it shares a sequence of letters and a common sound with many other words (e.g., might, sight, tight). It has been argued that the child who uses rime units is in a position to exploit this regularity, whereas the child who relies solely on grapheme-phoneme correspondences, is not (Goswami, 1990a; Goswami \& Bryant, 1990). It has also been found that the unpredictable nature of the English orthography may encourage readers to use rime units (Treiman et al., 1995), and that children have been shown to be able to successfully use rime units as a means of coping with this unpredictability (Goswami, Gombert, \& De Berra, 1998).

It is also argued that a focus on rimes offers large gains in the consistency of vowel pronunciations because the pronunciation of vowels is more stable within, than across, rime groups (Tunmer \& Chapman, 1999). Goswami (1999a) points out that the letter $a$ represents many different sounds (e.g., in cat, ball, car, day, saw, cake, and care) but that these different phoneme correspondences are consistent across rhyming groups (e.g., in cat, mat, bat; ball, fall, wall; care, stare, dare). Johnson (1999) has argued for the use of rimes as the basis for vowel instruction for beginning readers because vowels then need not be labelled in any particular way - at least at initial stages of reading instruction. Thus the beginning reader no longer has to struggle with whether a vowel sound is, for instance, short or long or "l" or " $\mathrm{r}$ " controlled (e.g., call, chalk; car, chart) because the child simply learns to associate the sound with the rime.

\section{Levels of phonological awareness}

A further focus of the small-versus large-unit debate centres on the use of rhyme-oddity task results to argue that Goswami's theory of the early availability of rhyme is invalid (Duncan et al., 2000). (Note that Bradley and Bryant's (1978) rhyme-oddity taskinvolves a child hearing three or four words, and being asked to identify the word that does not rhyme, for example, pin, win, tin, sit). This type of task, it has been argued, measures a preliminary phonological awareness, while those involving the segmentation or manipulation of phonemes measure a more complex level (Castle, 1999; Morais, 1991; Stanovich, 1992; Tunmer \& Rohl, 1991)

Duncan et al. use Gombert's (1992) theory on the distinction between epilinguistic (i.e., implicit or unconscious) phonological awareness and metalinguistic (i.e., explicit or conscious) phonological awareness as the basis of their argument. They argue that it can not be assumed that a child who can perform a task measuring epilinguistic awareness of a speech segment (such as the rhyme-oddity task) will also have a metalinguistic awareness of that segment. They demonstrate that children with an excellent epilinguistic awareness of rhyme are nonetheless unable to identify the rime segment shared by two rhyming words (see also Duncan et al. 1997; Seymour et al. 1999). They also point to Morais (1991) who demonstrated that illiterate poets, whose epilinguistic awareness of rhyme was very highly developed, were unable to explain the part played by particular linguistic segments in rhyme-making. This evidence is then used to argue that Goswami's (1986, 1988) results are invalid since she used a rhyme-oddity task (a measure of epilinguistic awareness) to demonstrate that young children have an awareness of rhyme, and phoneme segmentation and manipulation tasks (measures of metalinguistic awareness) to demonstrate that they do not have an awareness of phonemes. In doing so, it is argued, Goswami confuses the implicit and explicit awareness of phonological units, appearing to assume they are one and the same (Macmillan, 2002).

In response, Goswami and East (2000), while agreeing that the rhyme awareness which children bring with them when they start school represents an implicit or epilinguistic awareness, take a radically different perspective. They first argue that much of what we know is known implicitly, that we routinely use implicit knowledge to solve cognitive tasks, and that even though implicit knowledge cannot be verbalized, it is, nonetheless, knowledge that the knower possesses and uses. Thus, this theory implies a status for implicit knowledge that is not evident in Duncan et al. and Seymour et al. discussed above. Goswami and East's theory differs on a second crucial point. It is argued that implicit knowledge remains in the child's mind, even after 
their awareness of a particular linguistic segment has become explicit, so that they eventually hold multiple representations of similar knowledge at different levels of detail and explicitness. Therefore, it is possible that either or both epi-and meta-levels of awareness might be involved in the development of a body of information about phonological segments that could be used in order to respond in a phonological awareness task. It may not, therefore, be possible to state definitively which level of awareness a child has used in order to respond to a phonological awareness task. On both points Goswami and East may be closer than Duncan et al. and Seymour et al. to Gombert's work. Gombert not only warns against trying to experimentally demonstrate both the conscious character of an activity and the degree of consciousness it implies; he also argues that different levels of consciousness may coexist within the same activity.

In the light of the above debate, I would contend that the argument in favour of teaching only small units at the outset of reading instruction is the more compelling. It presents a clearer and more consistent picture of beginning reading behaviour, while the large-units-at-the-outset literature has yet to adequately dispel doubts concerning phonological priming, the small numbers of rimes available as analogues to beginning readers, and the minimal use of beginning readers in the research.

\section{The Ready to Read Teacher Support Material}

The activities presented in Sound Sense (the section of the Ready to Read Teacher Support Material focusing specifically on phonological awareness and phonics) begin by focusing on identifying rhymes and differentiating between words that do, and do not, rhyme. The section ends with activities that involve listening for initial and ending sounds, and sounds in sequence within words (i.e., listening for individual phonemes). This represents an implicit agreement that children's earliest phonological awareness is about rhyme. The initial focus is primarily aural, with print-based (i.e., rime) instruction kept to a minimum. This may reflect an awareness of the mean reading age of subjects in most research demonstrating young children's ability to use a rime-analogy strategy - between six and a half years and seven years, and only very rarely below those levels.

A focus on phonics (i.e., the relationship between sounds and letters) follows the initial aural focus. The teaching suggestions given for the first five poems in this second topicinvolve matching individual phonemes (i.e., initial consonants, blends, and digraphs) with graphemes - none involve rimes. This is followed by a focus on medial vowel sounds for the next seven poems, where it is suggested that vowels be taught as part of rimes. Since rimes are only introduced after work on small units, a degree of reserve in advocating the teaching of rime-related strategies as soon as children begin school is indicated.

The texts at Emergent level (identified by the colour Magenta) follow the same general pattern. The Emergent reader is characterized as having a beginning understanding of the concepts of letter and word, and as showing pleasure in rhythm and rhyme - there is no mention of rime units. Significantly, there is no appendix supplied for the repeated rimes used at this level, whereas they are supplied for both the Sound Sense section and Early level section which follows the Emergent level.

No use of rhymes was made at the Magenta level, in order to make irregularly spelled words, such as those containing " 1 " or " $\mathrm{r}$ " controlled vowels, easier to read (Goswami, 1990a; Goswami \& Bryant, 1990; Goswami, Gombert, \& De Berra, 1998; Treiman, 1992; Treiman, Mullenix, Bijeljac-Babic, \& Richmond-Welty, 1995). Attention to irregular rime spellings is not made until Red (the first set of Early texts), where rimes such as "all" and "irt" are highlighted. The notes at Magenta and Red levels also suggest a certain hesitancy towards teaching rime-related strategies at the outset of instruction by neglecting to take advantage of the rimes presented through high frequency vocabulary. Even though high frequency vocabulary is a significant aspect of the text features at Magenta and Red levels, attention is not often drawn to the rimes exhibited by words such as at, and, can, get, in, like, look, my, we, and went - all of which contain rimes with large neighbourhoods (Leslie \& Calhoon, 1995; Calhoon \& Leslie, 2002). It also appears that Goswami's (1999a) contention that children's sensitivity to the frequency with which rimes occur in their reading vocabularies is crucial in using rime-analogy strategies, and that their sensitivity will be increased through teaching rimes with large neighbourhoods at the outset of reading instruction, has received only qualified support. For, while the rimes presented at Magenta level do have large neighbourhoods (e.g., "an", "at"), less than half the notes at that level contain rime-related teaching suggestions (see Table 1). This indicates support for the argument that rimes with large 
neighbourhoods should be taught before those with small neighbourhoods, but limited support for the teaching of rime-analogy strategies as soon as reading instruction begins. Although at Magenta level just over three-quarters of the text notes contain graphemerelated suggestions, it is not until Red level that nearly three quarters of the text notes contain rime-related suggestions (see Table 1).

Table 1 Text notes containing rime- and grapheme-related teaching suggestions

\begin{tabular}{|c|c|c|c|c|c|c|}
\hline \multirow[t]{2}{*}{ Level } & \multirow[t]{2}{*}{ Colour } & \multirow[t]{2}{*}{ No. of texts } & \multicolumn{2}{|c|}{$\begin{array}{l}\text { Text notes containing } \\
\text { rime-related } \\
\text { suggestions }\end{array}$} & \multicolumn{2}{|c|}{$\begin{array}{l}\text { Text notes containing } \\
\text { grapheme-related } \\
\text { suggestions }\end{array}$} \\
\hline & & & $\mathrm{N}$ & $\%$ & $\mathrm{~N}$ & $\%$ \\
\hline \multirow{5}{*}{$\begin{array}{l}\text { Emergent } \\
\text { Early }\end{array}$} & Magenta & 25 & 10 & 40 & 19 & 76 \\
\hline & Red & 27 & 19 & 70 & 27 & 100 \\
\hline & Yellow & 17 & 14 & 82 & 15 & 88 \\
\hline & Blue & 13 & 9 & 69 & 13 & 100 \\
\hline & Green & 21 & 19 & 90 & 20 & 95 \\
\hline
\end{tabular}

In the general information provided in both Sound Sense (p. 35) and the Early text notes (p. 20) it is stated that vowels are best introduced within rimes rather than as individual letters because of the variety of sounds associated with each vowel. But even though vowels are indeed introduced as part of a rime, they are promptly extracted from it, and the individual vowel, either short or long, becomes the focus all this occurs within one lesson. This indicates a reluctance to use rime units to the extent suggested by Johnson (1999) when she argues that vowels need not be labelled in any particular way for beginning readers; instead, beginning readers need only learn to match the sound with the spelling of the rime. This kind of use of rimes to teach vowels is perhaps best described in terms of a temporary support, leading on to a focus on individual phonemes - although the support provided is far more temporary than that envisaged by either Goswami (1990a, 1990b, 1999a) or Tunmer (1994).

The hesitancy with which the materials approach the use of rime units at Magenta level, however, must not be inferred as a rejection of rime-related strategies at this level; it is better regarded as a cautious initial use of rime units, that leads, in general, to a more confident use.
Even though the Emergent reader is not characterized as having an ability to use rime units (p. 3), the Early reader is characterized as not only associating sounds with individual letters, but also with associating sounds with clusters of letters (p. 5). This progression towards larger units is reflected in the number of text notes that contain rime-related teaching suggestions. (Rime- and graphemerelated teaching suggestions are defined, for the purposes of this discussion, as ones where reference is made to a rime or grapheme unit and an analogy strategy is used - the words rime, grapheme, and analogy need not necessarily be mentioned.) Although the notes at Blue level represent somewhat of an aberration, with only 69 percent containing rime-related suggestions, a general trend towards an increased use of rime units can be seen. At the very least, a clear distinction is evident when the Magenta and Green percentage levels are compared (Table 1).

The hesitant use of rime-related analogy strategies in Sound Sense and the Emergent level teaching suggestions may, again, reflect an awareness of the mean reading age of subjects in most of Goswami's research - between six years six months and seven years. This reading age is considerably higher than that of Emergent readers, which, even though the Ready to Read texts are not levelled according to reading age, can be inferred to be approximately five years (Ministry of Education, 2003, p. 71). This initial hesitancy may also reflect due recognition of claims by Seymour et al. (1999) that it may not be until the age of seven that most children can use rime-analogy strategies. However, it does appear that the Support Material reflects a much less cautious stance.

Support for the large-units-from-the-outset argument can also be found in the general Emergent notes (p. 11), when "implicit" learning, such as children's drawing of inferences about particular letter-sound relationships, is encouraged. This can be argued to be support for Goswami and East's (2000) argument that much of what we know is known implicitly, and that we routinely use implicit knowledge to solve cognitive tasks. It, therefore, can be suggested that the materials represent a lack of support for arguments (see Duncan et al., 1997, 2000; Seymour et al., 1999) that privilege explicit knowledge through a claim that children need a metalinguistic awareness of rime before they can use rime-analogy strategies. 


\section{Conclusion}

It is evident that aspects of both the argument in favour of teaching rime-analogy strategies as soon as children start school, and the argument in favour of teaching only small units to beginning readers, have influenced the development of the Ready to Read Teacher Support Material. However, it is also evident that the small-units-first argument has been relatively more influential. If the large-units-from-the-outset argument had been accepted in total, Sound Sense would have included rime-related suggestions from the very beginning - the initial focus of this section would not have been entirely aural. Sound Sense would also have introduced grapheme-phoneme relationships and rime-analogy strategies at the same point, rather than introducing grapheme-phoneme relationships first. The notes at Emergent level would have characterized the reader as able to use rime-related strategies, and an appendix of repeated rimes used in texts would have been supplied. Emergent text notes would also have made use of rimes to teach irregularly spelled words, and much more use would have been made of the rimes within high frequency words at both Magenta and Red levels. The support material would also have focussed on teaching rime units to beginning readers at the very outset, instead of teaching them to distinguish between short and long vowels.

However, had the argument in favour of teaching only small units to beginning readers been accepted in total, the notes at Emergent level would not have contained any rime-based teaching suggestions, whereas in fact, 40 percent do. Implicit knowledge would also not have been recognized as valid.

Support material which represents a selection of arguments from opposing theories could, of course, present confused or even rather insipid suggestions due to its not being strongly tied to either extreme. This material, however, is neither confused nor insipid, because the suggestions are presented not as prescriptive instructions for teachers to follow-step-by-step, but as an eclectic series of suggestions from which teachers can choose the most appropriate for their children. The sets of references given in the material reveal the influence of reports from the Literacy Taskforce (1999), the Literacy Experts Group (1999), and the work of McNaughton (1999), and Pressley (1998), all of which argue against taking an extreme position in the phonics versus whole language debate, where at times, the needs of children have become secondary to philosophical discussion. Lessons have been learnt from that earlier debate, with the support materials reflecting the philosophy that effective reading instruction does not rely on a singular approach. Instead, a flexible use of a range of both large- and small-unit strategies is presented as most effective, with the needs of the learner determining the strategies taught.

Now that teachers have support material that encourages the flexible use of a range of strategies, the next necessary addition to the Ready to Read folder of notes is material designed to help teachers make the most accurate assessment of learning needs, and to select the most appropriate suggestion according to those needs. At present, although teachers are provided with a wide range of teaching suggestions, there is no explicit guidance regarding how to analyse children's reading and writing in order to determine if a child's learning needs are best addressed with, for instance, rime- or phoneme-level strategies (or indeed, if learning needs are best addressed with context-related strategies). Teachers now need more support with the assessment of specific learning needs, and with the selection of the most appropriate strategies to meet those needs.

\section{References}

Bowey, J. A. \& Hansen, J. (1994). The development of orthographic rimes as units of word recognition. Journal of Experimental Child Psychology, 58, 465-488.

Bowey, J. A. \& Underwood, N. (1996). Further evidence that orthographic rime usage in nonword reading increases with word-level reading proficiency. Journal of Experimental Child Psychology, 63, 526-562.

Bowey, J. A., Vaughan, L., \& Hansen, J. (1998). Beginning readers' use of orthographic analogies in word reading. Journal of Experimental Child Psychology, 68, 108-133.

Bradley, L. \& Bryant, P. E. (1978). Difficulties in auditory organization as a possible cause of reading backwardness. Nature, 271, 746-747.

Bradley, L. \& Bryant, P. E. (1983). Categorising sounds and learning to read: A causal connection. Nature, 310, 419-421.

Bryant, P. E. (1998). Sensitivity to onset and rhyme does predict young children's reading: A reply to Muter, Hulme, Snowling, and Taylor. (1997). Journal of Experimental Child Psychology, 71, 29-37. 
Bryant, P. E., MacLean, M., Bradley, L., \& Crossland, J. (1990). Rhyme, alliteration, phoneme detection, and learning to read. Developmental Psychology, 26, 429-438.

Calhoon, A., \& Leslie, L. (2002). A longitudinal study of the effects of word frequency and rime-neighbourhood size on beginning readers' rime reading accuracy in words and nonwords. Journal of Literacy Research, 34(1), 39-58.

Castle, J. M. (1999). Learning and teaching phonological awareness. In G. B. Thompson \& T. Nicholson (Eds.), Learning to read: Beyond phonics and whole language (pp. 55-73). Newark, DE: New York: International Reading Association, Teachers College Press.

Clymer, T. (1963). The utility of phonic generalizations in the primary grades. The Reading Teacher, 16, 252-259.

Duncan, L. G., Seymour, P. H. K., \& Hill, S. (1997). How important are rhyme and analogy in beginning reading? Cognition, 63, 171-208.

Duncan, L. G., Seymour, P. H. K., \& Hill, S. (2000). A small-to-large unit progression in metaphonological awareness in reading? The Quarterly Journal of Experimental Psychology, 53A(4), 1081-1104.

Ehri, L. C. (1992). Reconceptualizing the development of sight word reading and its relationship to decoding. In P. B. Gough, L. C. Ehri, \& R. Treiman (Eds.), Reading acquisition (pp. 107-143). Hillsdale, NJ: Erlbaum.

Ehri, L. C. (1995). Phases of development in learning to read words by sight. Journal of Research in Reading, 18(2), 116-125.

Ehri, L. C. (1998). Grapheme-phoneme knowledge is essential for learning to read words in English. In J. L. Metsala \& L. C. Ehr (Eds.), Word recognition in beginning literacy (pp. 3-40). Mahwah, NJ: Erlbaum.

Ehri, L. C. \& Robbins, C. (1992). Beginners need some decoding skill to read words by analogy. Reading Research Quarterly, 27(1), 12-28.

Gombert, J. E. (1992). Metalinguistic development. London: Harvester Wheatsheaf.

Goswami, U. (1986). Children's use of analogy in learning to read: A developmental study. Journal of Experimental Child Psychology, 42, 73-83.

Goswami, U. (1988). Orthographic analogies and reading development. Quarterly Journal of Experimental Psychology, 40A, 239-268.

Goswami, U. (1990a). A special link between rhyming skill and the use of orthographic analogies by beginning readers. Journal of Child Psychology and Psychiatry, 31(2), 301-311.

Goswami, U. (1990b). Phonological priming and orthographic analogies in reading. Journal of Experimental Child Psychology, 49, 323-340.

Goswami, U. (1993). Toward an interactive analogy model of reading development: Decoding vowel graphemes in beginning reading Journal of Experimental Child Psychology, 56, 443-475.

Goswami, U. (1999a). Causal connections in beginning reading. Journal of Research in Reading, 22(3), 217-240.

Goswami, U. (1999b). Orthographic analogies and phonological priming: A comment on Bowey, Vaughan, and Hansen. (1998). Journal of Experimental Child Psychology, 72, 210-219.

Goswami, U., \& Bryant, P. E. (1990). Phonological skills and learning to read. Hillsdale, NJ: Erlbaum.

Goswami, U. \& East, M. (2000). Rhyme and analogy in beginning reading: Conceptual and methodological issues. Applied Psycholinguistics, 21, 63-93.

Goswami, U., Gombert, J. E., \& De Berra, L. C. (1998). Children's orthographic representations and linguistic transparency: Nonsense word reading in English, French, and Spanish. Applied Psycholinguistics, 19, 19-52.

Gough, P. B., Juel, C., \& Griffith, P. L. (1992). Reading, spelling, and the orthographic cipher. In P. B. Gough, L. C. Ehri, \& R. Treiman (Eds.), Reading acquisition (pp. 35-48). Hillsdale, NJ: Erlbaum.

Hulme, C., Hatcher, P. J., Nation, K., Brown, A., Adams, J., \& Stuart, G. (2002). Phoneme awareness is a better predictor of early reading skill than onset-rime awareness. Journal of Experimental Child Psychology, 82, 2-28.

Johnson, F. R. (1999). The timing and teaching of word families. The Reading Teacher, 53(1), 64-75.

Leslie, L. \& Calhoon, A. (1995). Factors affecting children's reading of rimes: Reading ability, word frequency, and rime-neighbourhood size. Journal of Educational Psychology, 87, 576-586.

MacLean, M., Bryant, P. E., \& Bradley, L. (1987). Rhymes, nursery rhymes, and reading in early childhood. Merrill-Palmer Quarterly, 33, 255-281.

Macmillan, B. M. (2002). Rhyme and reading: A critical review of the research methodology. Journal of Research in Reading, 25(1), 4-42. 
McNaughton, S. (1999). A reading of the Literacy Taskforce report. (1999). Teachers and Curriculum, 3, 5-9.

Ministry of Education. (1999). Literacy Experts Group report to the Secretary for Education. Wellington: Learning Media.

Ministry of Education. (1999). Report of the Literacy Taskforce. Wellington: Learning Media.

Ministry of Education. (2001, 2002, 2003). Ready to Read teacher support material. Wellington: Learning Media.

Ministry of Education. (2003). Effective literacy practice in years 1 to 4 . Wellington: Learning Media.

Morais, J. (1991). Constraints on the development of phonemic awareness. In S. A. Brady \& D. P. Shankweiler (Eds.), Phonological processes in literacy: A tribute to Isabelle Y. Lieberman (pp. 5-27). Hillsdale, NJ: Erlbaum.

Morais, J., Cary, L., Algeria, J., \& Bertelson, P. (1979). Does awareness of speech as a sequence of sounds arise spontaneously? Cognition, 7, 323-331.

Moustafa, M. (1997). Beyond traditional phonics: Research discoveries and reading instruction. Portsmouth, $\mathrm{NH}$ : Heinemann.

Muter, V., Snowling, M., \& Taylor, S. (1994). Orthographic analogies and phonological awareness: Their role and significance in early reading development. Journal of Child Psychology and Psychiatry, 35, 293-310.

Muter, V., Hulme, C., Snowling, M., \& Taylor, S. (1997). Segmentation, not rhyming, predicts early progress in learning to read. Journal of Experimental Child Psychology, 65, 370-396.

Pressley, M. (1998). Reading instruction that works: The case for balanced teaching. New York: Guilford Press.

Savage, R., \& Stuart, M. (1998). Sublexical inferences in beginning reading: Medial vowel digraphs as functional units of transfer. Journal of Experimental Child Psychology, 69, 85-108.

Seymour, P. H. K., Duncan, L. G., \& Bolik, F. M. (1999). Rhymes and phonemes in the common unit task: Replications and implications for beginning reading. Journal of Research in Reading, 22(2), 113-130.

Stanovich, K. E. (1992). Speculations on the causes and consequences of individual differences in early reading acquisition. In P. B. Gough, L. C. Ehri, \& R. Treiman (Eds.), Reading acquisition (pp. 307-342). Hillsdale, NJ: Erlbaum.
Treiman, R. (1985). Onsets and rimes as units of spoken syllables: Evidence from children. Journal of Experimental Child Psychology, 39, 161-181.

Treiman, R. (1992). The role of intrasyllabic units in learning to read and spell. In P. B. Gough, L .C. Ehri, \& R. Treiman (Eds.), Reading acquisition (pp. 65-106). Hillsdale, NJ: Erlbaum.

Treiman, R., Goswami, U., \& Bruck, M. (1990). Not all nonwords are alike: Implications for reading development and theory. Memory and Cognition, 18, 559-567.

Treiman, R., \& Zukowski, A. (1991). Levels of phonological awareness. In S. A. Brady \& D. P. Shankweiler (Eds.), Phonological processes in literacy: A tribute to Isabelle Y. Liberman (pp. 67-83). Hillsdale, NJ: Erlbaum.

Treiman, R., Mullenix, J., Bijeljac-Babic, R., \& Richmond-Welty, E. D. (1995). The special role of rimes in the description, use and acquisition of English orthography. Journal of Experimental Psychology, General, 124, 107-136.

Tunmer, W. E. (1994). Phonological processing skills and reading remediation. In C. Hulme \& M. Snowling (Eds.), Reading development and dyslexia (pp. 147-162). London: Whurr.

Tunmer, W. E. \& Chapman, J. W. (1999). Teaching strategies for word identification. In G. B. Thompson \& T. Nicholson (Eds.), Learning to read: Beyond phonics and whole language (pp. 74-102). Newark, DE: New York: International Reading Association, Teachers College Press.

Tunmer, W. E. \& Rohl, M. (1991). Phonological awareness and reading acquisition. In D. J. Sawyer \& B. J. Fox (Eds.), Phonological awareness in reading: The evolution of current perspectives (pp. 1-30). New York: Springer-Verlag.

Wise, B. W. (1992). Whole words and decoding for short-term learning: Comparisons on a "talking computer" system. Journal of Experimental Child Psychology, 54, 147-167.

Wood, C. (2002). Orthographic analogies and phonological priming effects. Journal of Research in Reading, 25(2), 144-159.

\section{The author}

Juliet Twist has worked as a primary school Assistant Principal, and has also written resources for teachers and parents supervising children's schoolwork. Areas of particular interest include literacy, assessment, and ESOL. Email: twistj@xtra.co.nz 